\title{
Da relação de condição no português: formas e sentidos
}

\author{
On conditional relation in Portuguese: structure and \\ meaning
}

\author{
Taísa Peres de Oliveira \\ UFMS/Grupo de Pesquisa em Gramática Funcional - UNESP
}

\begin{abstract}
This paper aims at providing an account for conditional marking on Brazilian Portuguese. In order to do so, conditional conjunctions were considered as they are listed by the grammars of Portuguese. The studied carried out here shows there is a wide group of conditional conjunctions, though the specialized literature focus on the conjunction se 'if' only. The analysis revealed that conditionality is realized by the expression of different conditional meanings, here called positive restrictive, negative restrictive and hypothetic. Moreover, taking into account that conditional markers have different meanings, conditional clauses were also analyzed in order to verify whether the different meanings can bring any influence over the clause construction. In order to do that, this paper analyzed conditionals clauses in the terms of the modifier typology put forward by Functional Discourse Grammar. As a result, we found out that the conditional meaning of the marker has no effect over the clause.
\end{abstract}

Keywords

Conditional conjunctions; positive restrictive; negative restrictive and hypothetic 


\section{Resumo}

O objetivo principal do estudo que se apresenta é verificar a expressão da condicionalidade na língua portuguesa. Nesse sentido, faz-se um levantamento das conjunções condicionais nessa língua, a partir das conjunções arroladas nos compêndios gramaticais. Verifica-se que, embora os estudos descritivos sobre as orações condicionais centrem seu foco de interesse na oração condicional iniciada pela conjunção se, expediente canônico para a expressão da relação de condição, outras conjunções e locuções conjuntivas concorrem para atualizar o sentido condicional. Além disso, o estudo mostra que a condicionalidade se realiza na expressão de diferentes sentidos, subdividindo as conjunções condicionais em três grupos: restritivas positivas, restritivas negativas, hipotéticas. Considerando-se os sentidos expressos pelas conjunções, procurou-se investigar se a conjunção tem alguma influência sobre a oração condicional que ela introduz. Para tanto, considerou-se a tipologia dos modificadores oracionais, tal qual a teoria da Gramática Discursivo Funcional propõe. O que se verificou é que o sentido expresso pela conjunção não opera sobre a configuração formal da oração que ela introduz.

\section{Palavras-chave}

Conjunções condicionais; restritivas positivas; restritivas negativas; hipotéticas. 


\section{Introdução}

$\mathrm{N}$

o português do Brasil, além da conjunção se, diversas conjunções complexas - tradicionalmente denominadas locuções conjuntivas atuam na expressão da relação condicional, tais como desde que, contanto que, sem que, a menos que, salvo se, entre outras. No entanto, apesar da grande variedade de conectores, em geral os trabalhos que se ocupam da expressão da condicionalidade dedicam-se apenas à oração condicional com se e raramente centram seu foco de interesse sobre as demais conjunções condicionais. Assim, com exceção dos trabalhos sobre gramaticalização de conjunções, essas locuções têm sido negligenciadas nos estudos sobre a condicionalidade, que se limitam a mencionar sua existência.

Desse modo, no estudo que ora se apresenta, pretende-se fazer um levantamento das diversas conjunções condicionais do português. Além disso, pretende-se ainda verificar as possíveis diferenças existentes entre as conjunções encontradas e as possíveis consequências formais que essas diferenças podem causar.

\section{As conjunções condicionais}

No português, assim como em outras línguas românicas (espanhol, italiano, romeno, francês, etc.), a conjunçãoé o expediente formal mais comum para marcar a relação condicional. ${ }^{1}$ Uma revisão nos compêndios gramaticais revela que, desde o latim, várias conjunções são empregadas para estabelecer a relação condicional. Faria (1958) apresenta, para o latim, além do $\boldsymbol{s i}$ (se), as conjunções nisi (se não), ni (se não), $\sin$ (se pelo contrário), modo (contanto que) e dummôdo (contanto que).

No português arcaico, ${ }^{2}$ segundo mostrou Barreto (1999) em seu estudo sobre a gramaticalização de conjunções no português, além do se, atuavam também as conjunções salvo se, salvo que, contanto que, nom que, fora, fora que, fora se, senon tanto se, ergo, marcar que. 
Esse quadro sofre uma drástica redução no português moderno (séc. XVI a séc. XVII), que apresenta as conjunções condicionais se, mais que, que, e senão. O quadro seguinte, adaptado de Barreto (1999, p. 45, v. III), traz as conjunções condicionais do latim ao português moderno, passando pelo português arcaico:

\section{QUADRO 1}

Conjunções Condicionais

\begin{tabular}{l|l}
\hline \multirow{4}{*}{ Latim clássico } & si (se) \\
& $n i s i$ (se não) \\
& $n i$ (se não) \\
& sin (se pelo contrário) \\
& modo (contanto que) \\
& dummodo (contanto que) \\
\hline & se \\
& se/salvo sse \\
& salvo que \\
Português arcaico & contanto que \\
(séc. XIII a séc. XV) & nom que \\
& fora \\
& fora que \\
& fora se \\
& senon tanto se \\
& ergo \\
& marcar que \\
& se \\
& mais que \\
Português moderno & que \\
& senão \\
\hline
\end{tabular}

No português contemporâneo, além do se, conjunção condicional herdada do latim, há, conforme se mencionou na introdução deste estudo, uma grande variedade de conjunções, o que pode ser observado no seguinte quadro, elaborado com base em uma revisão dos compêndios gramaticais da língua portuguesa: 


\section{QUADRO2}

Conjunções Condicionais do Português Contemporâneo

\begin{tabular}{c|l}
\hline Rocha Lima (1972) & $\begin{array}{l}\text { Se, caso, contanto que, sem que, uma vez que, dado que, } \\
\text { desde que, etc. }\end{array}$ \\
\hline Bechara (2004) & $\begin{array}{l}\text { Se, caso, sem que, uma vez que (com verbo no subjuntivo), } \\
\text { dado que, contanto que, etc. }\end{array}$ \\
\hline Luft (1989) & $\begin{array}{l}\text { Se, caso, sem que (se não), uma vez que, a não ser que, } \\
\text { exceto se, a menos que, etc. }\end{array}$ \\
\hline Neves (2000) & $\begin{array}{l}\text { Se, caso, que, desde que, contanto que, uma vez que, a } \\
\text { menos que, sem que, a não ser que, salvo se, exceto se. }\end{array}$ \\
\hline
\end{tabular}

Essa diversidade, entretanto, foi muito pouco explorada. Os estudos que tratam da condicionalidade, em geral, centram seu foco de interesse na oração condicional em si, tal como se vê, para o português especificamente, nos trabalhos de Gryner (1995), Ferreira (1997), Hirata (1999), Decat (1999), Neves (1999), entre outros. Assim, muito pouco foi feito a respeito da conjunção condicional. De fato, no que diz respeito ao português, à exceção de Neves (2000), nos diferentes autores citados acima nenhuma alusão é feita às possíveis diferenças existentes entre as diversas conjunções e locuções conjuntivas arroladas.

Montolío (2000) afirma que a ausência de estudos sobre as locuções conjuntivas se deve ao fato de as diferentes conjunções serem tratadas como equivalentes. Neste trabalho acredita-se que essa predileção pelas condicionais iniciadas pela conjunção se é devido ao fato de ela ser a mais comum entre as conjunções condicionais, funcionando como o elemento prototípico da relação condicional.

Os diferentes sentidos que as conjunções condicionais manifestam podem ser observados nos exemplos (01)-(03). Neles verificam-se não apenas as diferenças de sentido que existem entre as conjunções e as locuções conjuntivas condicionais, mas também o fato de que elas não podem ser consideradas equivalentes.

(01) A não ser que ele vá eu vou.

(02) Somente se ele for eu vou.

(03) Se ele for eu vou. 
Os três conectores exemplificados em (01)-(03) especificam diferentes sentidos $^{3}$ para a relação condicional. Em (01), o conector especifica o evento descrito na oração condicional como condição única para a não realização do evento descrito na oração núcleo. Por outro lado, em (02), ocorre o inverso, uma vez que a locução conjuntiva restringe o evento contido na oração condicional como única condição em que o evento contido na oração núcleo se realiza. Por fim, o uso da conjunção se estabelece uma relação de condição mais ampla em (03), em que esses sentidos mais restritivos se perdem.

Essa diferença foi observada por Neves (2000) que, em sua gramática do português, descreve essa variação de sentido estabelecida pelas diferentes conjunções e locuções conjuntivas. Em seu trabalho, a autora mostrou que algumas locuções conjuntivas produzem uma leitura diferente daquela efetivada pelo se. Neves (2000, p. 843) afirma que, em construções iniciadas por somente se e só se, "os conteúdos proposicionais da prótase e da apódose têm de ser ou ambos verdadeiros, ou ambos falsos (graças à inferência solicitada)." A autora mostra ainda que há casos em que uma condição necessária e suficiente promove inversão de polaridade: é o que ocorre com o uso das locuções a não ser que, a menos que, salvo se e exceto se. Os seguintes exemplos, extraídos dessa autora, ilustram, respectivamente, esses casos:

(04) Artes por essas bandas, meu irmão, $\boldsymbol{S O} \boldsymbol{S} \boldsymbol{E}$ for a de furtar. (p. 843)

(05) Enterrado ou fora da sepultura, o zumbi permanecia como morto, dez horas, A MENOS QUE continuasse sendo alimentado (...) (p. 845)

Essa mesma diferença já havia sido observada também por Visconti (1996) em seu estudo sobre as locuções conjuntivas do inglês e italiano. A autora sugere uma distinção tripartite para as locuções conjuntivas condicionais e as classifica em: hipotéticas, restritivas positivas e restritivas negativas.

As conjunções hipotéticas introduzem a proposição veiculada pela oração condicional como a condição da qual a proposição veiculada pela oração núcleo é contingente. Para as construções introduzidas por esse tipo de conjunção, Visconti (1996) propõe a leitura "considere $q$ na situação dada por $p$ ". As construções seguintes (06) e (07) exemplificam alguns desses casos: 
(06) Nel caso in cui/casomai fossero in ritardo, possiamo sempre aspettarli al bar (p. 569)

No caso em que eles estivessem atrasados poderíamos sempre esperá-los no bar.

(07) However, in the event of an emergency situation in a third country posing a threat of a sudden inflow of nationals from that country into the Community, the Council [...] may introduce, for a period not exceeding six months, a visa requirement for nationals from the country in question. (p. 551)

Entretanto, no caso de uma situação de emergência num terceiro país provocando a ameaça de um aumento repentino de cidadãos daquele país na Comunidade, o Conselho [...] pode introduzir, por um período não excedente a seis meses, um pedido de visto para os cidadãos do país em questão.

As conjunções restritivas positivas introduzem a proposição descrita na oração condicional como uma condição que limita a validade/contingência da proposição descrita na oração núcleo. As construções introduzidas por esse tipo de conjunção recebem a leitura " $p$ é a situação específica na qual $q$ ". Abaixo seguem exemplos desse tipo de conjunção composta (VISCONTI, mimeo).

(08) Farò finta di niente, a patto che l'incidente non si ripeta. (p. 2) Farei de conta que nada aconteceu, contanto que o incidente não se repita.

(09) January 1957 shall, in so far as they serve only to compensate for the absence of customs protection, be progressively reduced under the same conditions as apply to the elimination of custom duties (Art. 92.3c). (p. 1)

Janeiro de 1957 deve, contanto que eles sirvam apenas para compensar a falta de proteção da alfândega, ser progressivamente reduzido às mesmas condições no que se aplica a eliminação das taxas alfandegárias.

No caso de uma conjunção restritiva negativa, segundo a autora, a proposição contida na oração condicional é apresentada como a única condição 
para que a proposição contida na oração núcleo não ocorra. Essas conjunções podem ser lidas por "não $p$ é a situação específica na qual $q$ ". Esse tipo é exemplificado pela conjunção do inglês unless:

(10) Unless it's raining we're going to the beach.

A não ser que esteja chovendo nós vamos à praia.

A diferença discutida anteriormente evidencia o fato de que as diversas conjunções condicionais se diferenciam não apenas em relação ao se, mas entre elas próprias. Dessa forma, os três diferentes sentidos especificados pelas conjunções condicionais compreendem parte da condicionalidade, que não pode ser totalmente compreendida sem que eles sejam explicados. Além disso, as diferenças não existem apenas no âmbito do tipo de relação condicional que as conjunções complexas atualizam, mas também no que diz respeito a sua própria estrutura interna. As conjunções se constituem a partir de diferentes bases lexicais e, dessa forma, é preciso investigar de que maneira essas diferenças se refletem no uso que é feito dessas conjunções.

\section{Conjunções condicionais no português}

Para a realização deste estudo, fez-se um levantamento no banco de dados do Laboratório de Lexicografia da Faculdade de Ciências e Letras da UNESP - Campus de Araraquara. Trata-se de um banco de dados do português escrito do Brasil, que contempla as seguintes modalidades de texto: (i) literatura romanesca; (ii) literatura dramática; (iii) literatura técnica, (iv) literatura jornalística; (v) literatura de propaganda; (vi) literatura de oratória.

Os dados que formam o corpus avaliado neste estudo foram coletados em um universo de 10 milhões de palavras, em um período predefinido que vai do ano de 1950 até o ano de 2000, considerando-se todas as modalidades de texto mencionadas no parágrafo anterior, contemplando, dessa forma, a situação enunciativa em diferentes contextos.

No português coexistem as conjunções se, caso, a não ser que, exceto se, salvo se, só/somente se, sem que, a menos que, contanto que, dado que, desde que. Assim, considerando-se os sentidos propostos por Visconti (1996; 2000; 2004), anteriormente discutidos, as conjunções podem ser classificadas em (i) restritiva positiva, (ii) restritiva negativa e (iii) hipotética. 
O maior grupo de conjunções condicionais do português é aquele que manifesta o significado restritivo positivo. Esse tipo de conjunção restringe o significado da oração condicional, de modo que a construção recebe a seguinte leitura:

- considere a realização/verdade/adequação pragmática da oração núcleo na condição única da realização/verdade/adequação pragmática da oração condicional, como pode ser observado na seguinte ocorrência:

(11) Somente se Zé Lino não aceitar é que Fares Lopes passará a analisar outros nomes.

Nesse caso, a relação condicional se estabelece de tal forma que as duas orações envolvidas se implicam mutuamente, istoé, são ambas verdadeiras ou ambas falsas. Éo que tem sido chamado na literatura de valor bicondicional (AWERA, 1983, VISCONTI, 1996, NEVES, 2000). Além da conjunção somente se, exemplificada em (11), esse significado é também atualizado pelas locuções só se, contanto que, desde que, dado que como se observa nas ocorrências a seguir.

(12) Motivo para acordar mais cedo só se for o horário de verão que dizem vir por aí.

(13) A rede de atendimento primário poderá ser constituída não só pelos estabelecimentos federais do INAMPS, mas também, por estabelecimentos estaduais e municipais, desde que estes se mostrem capacitados para exercer esse trabalho.

(14) O esgotamento no governo FHC propicia assim uma oportunidade histórica para a esquerda, contanto que ela saiba se oxigenar teórica e politicamente.

(15) O governo aceitaria contratos de diversas empresas, dado que estivessem de acordo com as normativas vigentes.

Atua, também, na expressão do significado restritivo positivo a locução sem que. A diferença entre esta e as outras conjunções exemplificadas é que, na oração condicional iniciada por sem que, o significado restritivo positivo se constrói por meio da combinação da conjunção sem que com negação na oração núcleo, como se observa no seguinte exemplo: 
(16) Isso significa que nós fazemos parte de um todo que não poderá crescer sem que cresçamos nós, também.

O segundo maior grupo de conjunções condicionais no português é aquele que tem significado restritivo negativo, no qual a conjunção restringe a relação condicional com inversão de polaridade, como já havia observado Neves (2000). Para esse tipo de conjunção, propõe-se a seguinte leitura:

- considere a realização/verdade/adequação pragmática da oração núcleo na condição única da não realização/verdade/adequação pragmática da oração condicional, como mostra a ocorrência.

(17) Não há significativos custos para os cofres públicos, a não ser que o governo local opere mal uma empresa pública ou subsidie o preço da passagem.

Nesse caso, a oração condicional é apresentada como uma condição para que o conteúdo da oração principal seja considerado não verdadeiro. Em outras palavras, nas construções iniciadas por esse tipo de conjunção, caso a oração condicional seja validada, segue necessariamente a não validação da oração núcleo, ou vice-versa. Além da conjunção a não ser que, atuam ainda na expressão do significado restritivo negativo as conjunções salvo se, exceto se e a menos que, como se vê a seguir.

(18) Produtos da zona não poderão ser reexportados pelos países importadores, salvo se houver prévio acordo com o país interessado.

(19) As duas camadas externas neuronais da retina geralmente permanecem sem lesões, exceto se oclusões vasculares estão superajuntadas.

(20) Passaremos de um problema de subemprego dos volantes para o de desemprego aberto, a menos que os outros setores da economia possam absorver esses contingentes de mão de obra liberados do campo.

O menor grupo de conjunções é aquele que tem significado hipotético. Conjunções desse tipo estabelecem uma relação condicional mais ampla. No 
entanto, embora seja menor grupo em variedade de conjunções, esse grupo é altamente produtivo, o que se deve ao fato de esse tipo de relação ser plenamente expresso pelo se, conjunção condicional canônica no português. Além do se, a conjunção caso também pode expressar essa relação. Para as conjunções com esse significado, propõe-se a seguinte leitura:

- considere a realização/verdade/adequação pragmática da oração núcleo no caso da realização/verdade/adequação pragmática da oração condicional, como se vê na seguinte ocorrência:

É o que se vê nos seguintes exemplos:

(21) Se chover assim no mês de fevereiro teremos que adiar a colheita.

(22) Caso ele seja respeitado pelos motoristas, os acidentes deverão diminuir bastante.

A diferença observada entre os três tipos de conjunção condicional encontrados no português pode ser interpretada segundo a Tese da Condicionalidade Suficiente (Sufficient Conditionality Thesis), elaborada por Awera (1983). As conjunções hipotéticas são aquelas que apresentam a oração condicional como uma condição suficiente para a realização do conteúdo descrito pela apódose. Daí a leitura "considere a realização/verdade/adequação pragmática da oração núcleo no caso da realização/verdade/adequação pragmática da oração condicional". O principal exemplo dessa conjunção no português é o se, como se vê no exemplo:

(23) Indubitavelmente haverá cidadania se os direitos sociais clássicos forem garantidos: acesso à educação, à saúde, saneamento básico, fidelidade da informação, digna qualidade da vida, avanços da ciência, cultura, etc.

Em (23), a condição descrita pela oração condicional 'direitos sociais clássicos forem garantidos' é apresentada como uma condição suficiente para a validação do conteúdo contido na oração núcleo 'haverá cidadania'. Em outras palavras, ao preenchimento da condição descrita pela oração condicional segue a eventual/possível realização da oração núcleo. 
Por outro lado, as conjunções restritivas positivas e as restritivas negativas apresentam a oração condicional como uma condição necessária para a validação ou não do conteúdo descrito pela oração núcleo. No caso das restritivas positivas, a realização da oração condicional leva necessariamente à realização da oração núcleo, implicando o fato de que a não realização da condicional leva necessariamente à não realização da oração núcleo. Daí a leitura “considere a realização/verdade/adequação pragmática da oração núcleo na condição única da realização/verdade/adequação pragmática da oração condicional". Isso é o que mostra o caso a seguir.

(24) A decisão unânime dos sete juízes da Suprema Corte da Flórida, na noite de terça-feira, de validar a recontagem manual de quase um terço dos votos das eleições presidenciais no Estado e ordenar sua inclusão no resultado final levará a uma resolução relativamente rápida para a disputa pela Casa Branca só se houver um desfecho desfavorável para seu principal beneficiário - ou seja, a derrota do democrata Al Gore diante do republicano George W. Bush.

No exemplo, a oração condicional 'só se houver um desfecho desfavorável para seu principal beneficiário’ é apresentada como uma condição necessária para a validação do conteúdo descrito pela oração núcleo. Desse modo, as orações condicionais se implicam mutuamente, ou seja, pela conjunção usada as orações são ambas verdadeiras ou ambas falsas.

Nas condicionais iniciadas por conjunções restritivas negativas, a oração condicional também é apresentada como uma condição necessária, mas nesse caso com inversão de polaridade, como se discutiu anteriormente. Assim, dada a ocorrência da oração condicional segue necessariamente a não ocorrência da oração núcleo e vice-versa. Por essa razão, a leitura "considere a realização/ verdade/adequação pragmática da oração núcleo na condição única da não realização/verdade/adequação pragmática da oração condicional", como na ocorrência a seguir.

(25) As reservas de matérias-primas da Terra se esgotarão no final do próximo século, a menos que a humanidade comece a explorar as riquezas do espaço. 
Nesse caso, a oração condicional 'a humanidade comece a explorar as riquezas do espaço' é apresentada como condição necessária para a não validação da oração núcleo 'as reservas de matérias-primas da Terra se esgotarão no final do próximo século'. Entretanto, caso a oração condicional seja validada, segue necessariamente a não validação da oração núcleo, ou seja, as orações são mutuamente excludentes.

As considerações apresentadas mostram que as conjunções condicionais do português constituem três grupos bem distintos a depender do sentido condicional que expressam. Os casos discutidos revelam que as conjunções condicionais não podem ser tratadas como equivalentes, já que manifestam diferentes sentidos, atendendo a propósitos comunicativos diferentes. Uma vez estabelecidos os tipos de conjunção condicional, resta saber se os diferentes sentidos que ela expressa podem influir sobre a estrutura da oração que ela introduz.

\section{Conjunções e orações condicionais}

$\mathrm{Na}$ Gramática Discursivo Funcional (doravante GDF), as orações condicionais são concebidas como um tipo de modificador oracional, que pode qualificar a predicação, a proposição ou o ato do discurso. Assim, três tipos de modificador condicional são distinguidos, considerando-se a camada com a qual a condicional está ligada:

- Modificador condicional retórico: quando a oração condicional oferece uma condição para a adequação/relevância comunicativa do ato do discurso com o qual se relaciona;

(26) John has left, in case you haven't heard.

John partiu, no caso de você não ter tomado conhecimento.

- Modificador condicional proposicional: quando a oração condicional oferece uma condição para a validação da proposição com a qual se relaciona;

(27) If John stays, Peter will leave

Se John ficar, Peter partirá. 
- Modificador condicional de predicação: quando a oração condicional oferece uma condição para a realização do estado-decoisas com o qual se relaciona.

(28) He'll take his umbrella in case of rain. ${ }^{4}$

Ele pegará seu guarda-chuva em caso de chuva.

As orações condicionais foram analisadas segundo a tipologia apresentada. Entre os três tipos de conjunção que foram identificados neste estudo, apenas conjunções com significado hipotético podem introduzir modificadores retóricos. Vejam o exemplo:

(29) - Sei, Sérgio. Felizmente, sei. O caminho de casa, por hoje. Porque, amanhã, será vida nova.

Se você pensa que vou continuar a aguentar sua estupidez, está muito enganado! Ainda uma vez, Sérgio sacudiu os ombros.

Nesse caso, a oração introduzida pela conjunção se traz uma condição para a adequação do ato do discurso contido na oração principal. Em outras palavras, a oração condicional se relaciona ao conteúdo veiculado pela oração principal, servindo como uma justificativa comunicativa para sua enunciação. É o que mostra a representação subjacente dessa oração.

(30) $\left(\mathrm{A}_{\mathrm{I}}:\left[\left(\mathrm{F}_{\mathrm{I}}: \mathrm{DECL}\left(\mathrm{F}_{\mathrm{I}}\right)\right)\left(\mathrm{P}_{\mathrm{I}}\right)_{\mathrm{s}}\left(\mathrm{P}_{\mathrm{J}}\right)_{\mathrm{A}}\left(\mathrm{C}_{\mathrm{I}}\right.\right.\right.$ : [está muito enganado] $\left.\left(\mathrm{C}_{\mathrm{I}}\right)\right)$ $\left(\mathrm{C}_{\mathrm{J}}\right.$ : [você pensa que vou continuar a aguentar sua estupidez $\left.\left.\left(\mathrm{C}_{\mathrm{J}}\right)\right)_{\text {Orientation }}\right]\left(\mathrm{A}_{\mathrm{I}}\right)$

Veja que a condicional se realiza como um conteúdo comunicado $\left(\mathrm{C}_{\mathrm{J}}\right)$ que atua sobre o conteúdo comunicado $\left(\mathrm{C}_{\mathrm{T}}\right)$, ambos formando o ato do discurso $\left(\mathrm{A}_{\mathrm{T}}\right)$. Nesse caso, a oração condicional serve para orientar o ouvinte acerca das intenções comunicativas do falante, expressas pelo conteúdo comunicado $\left(\mathrm{C}_{\mathrm{I}}\right)$, por isso a oração condicional recebe a função retórica de orientação. ${ }^{5}$ Assim, a relação de condição é estabelecida em termos unicamente discursivos, já que a oração condicional se relaciona com o ato do discurso.

É preciso mencionar que apenas a conjunção se pode introduzir esse tipo de oração condicional. Acredita-se que tal fato se deva ao estatuto gramatical dessa conjunção e a seu decorrente significado abstrato, não tendo relação com 
o tipo de significado condicional que ela manifesta. As demais conjunções, por ainda conterem um vestígio de significado lexical, não podem se ligar a unidades do nível interpessoal.

Os modificadores proposicionais e de predicação podem ser introduzidos por qualquer tipo de conjunção. No caso dos modificadores proposicionais, a oração condicional serve para qualificar a verdade da proposição contida na oração núcleo, isto é, a oração condicional se relaciona com uma proposição, oferecendo uma condição para que sua verdade seja validada. É o que se exemplifica a seguir:

(31) E o tal de feminismo, que tal lhe parece?

Analista De Bagé: pôs sou a favor. Acho que toda a mulher deve lutar pela sua igualdade, desde que não interfira com o serviço da casa. Depois de pendurar as roupas ela pode fazer o quem bem entender.

Falam da existência de uma nova mulher, uma nova moral, o tal de "novo pacto afetivo". O que o senhor acha ? (ANB-R)

$\left(\mathrm{p}_{\mathrm{i}}\right.$ : [Acho que toda a mulher deve lutar pela sua igualdade] $\left(\mathrm{p}_{\mathrm{i}}\right)$ $<\left(\mathrm{p}_{\mathrm{j}}\right.$ : [não interfira com o serviço da casa] $\left.\left(\mathrm{p}_{\mathrm{j}}\right)\right)\left(\mathrm{p}_{\mathrm{i}}\right)$

Veja que, nesse caso, a condicional se realiza como uma proposição $\left(\mathrm{p}_{\mathrm{j}}\right)$, que se liga à uma outra proposição $\left(\mathrm{p}_{\mathrm{i}}\right)$ veiculada na oração principal. Os modificadores condicionais de predicação descrevem um estado-de-coisas como resultado da realização de outro estado-de-coisas. É o que se vê no próximo exemplo.

(32) Não deixam de possuir estrutura cristalina, mas a forma externa (informe) não traduz o arranjo regular interno. A grande maioria dos minerais, entretanto, pode manifestar forma geométrica externa desde que as condições de crescimento tenham permitido. Os minerais se cristalizam em sete sistemas de simetria, a saber: monométrico, tetragonal, hexagonal, trigonal, ortorrômbico, monoclínico e triclínico. (PEP-T)

$\left(\mathrm{p}_{\mathrm{i}}:\left(\mathrm{e}_{\mathrm{i}}\right.\right.$ : A grande maioria dos minerais, entretanto, pode manifestar forma geométrica externa] $\left(e_{i}\right)>\left(e_{j}\right.$ : [as condições de crescimento tenham permitido] $\left.\left.\left(\mathrm{e}_{\mathrm{j}}\right)\right)\left(\mathrm{p}_{\mathrm{i}}\right)\right)$ 
Nesse caso, a relação condicional se dá no interior de uma proposição $\left(\mathrm{p}_{\mathrm{i}}\right)$, na qual um estado-de-coisas $\left(\mathrm{e}_{\mathrm{j}}\right)$ se apresenta como condição que deve ser preenchida para a realização de um outro estado-de-coisas $\left(e_{i}\right)$.

\section{Considerações Finais}

Neste artigo analisou-se a expressão da condicionalidade no português brasileiro. Pela análise das conjunções em dados reais de uso da língua, verificouse que, diferentemente do que mostram os compêndios gramaticais, a expressão da condicionalidade se dá de diferentes modos. A descrição das conjunções condicionais levada a cabo neste estudo mostrou que as diferentes conjunções condicionais encerram diferentes sentidos, podendo ser classificadas em: (i) restritivas positivas, (ii) restritivas negativas e (iii) hipotéticas.

As conjunções classificadas como restritivas positivas apresentam uma condição que limita a validação da oração núcleo, numa relação em que são ambas verdadeiras, ou ambas falsas. Por outro lado, as conjunções nomeadas restritivas negativas apresentam a oração condicional como a única condição para a não validação da oração núcleo, unindo-se numa relação em que ocorre uma polaridade inversa, ou seja, dada a validação da condicional, segue a não validação da núcleo, ou vice-versa. Por fim, as conjunções hipotéticas estabelecem uma relação mais ampla, na qual a oração condicional é apresentada como uma condição contingente na qual a oração núcleo se valida.

Além disso, buscou-se investigar neste artigo a hipótese de que aos diferentes sentidos manifestados pelas conjunções corresponderiam diferenças na configuração da oração condicional. Para tanto, considerou-se a tipologia dos modificadores oracionais, tal como elaborada na Gramática Discursivo Funcional. No entanto, as diferenças observadas entre as conjunções não se refletem na estrutura da oração condicional que elas introduzem, já que a descrição das orações condicionais realizada revelou não haver diferenças significativas no que diz respeito aos aspectos ao tipo de modificador que a oração condicional atualiza. 


\section{Notas}

${ }^{1}$ A junção oracional pode ser expressa também por justaposição, tal como em 'Tivesse eu me controlado, não estaria tão arrependido'.

${ }^{2}$ A periodização do português apresentada aqui segue aquela elaborada por Barreto (1999).

${ }^{3} \mathrm{O}$ termo sentido é usado para cobrir os valores expressos pelas conjunções condicionais complexas.

${ }^{4}$ Os exemplos 26-28 foram extraídos de Dik et al (1990, p. 34).

5 'Orientation' para manter adequação descritiva com o modelo.

\section{Referências}

BARRETO, T. M. M. Gramaticalização das conjunções na história do português. 1999. 326 f., v. I e II. Tese (Doutorado em Letras e Linguística) - Instituto de Letras - Universidade Federal da Bahia, Salvador, 1999.

BECHARA, E. Moderna Gramática Portuguesa. Rio de Janeiro: Lucerna, 2004.

FARIA, E. Gramática Superior da Língua Latina. Rio de Janeiro: Livraria Acadêmica, 1958.

DECAT, M. B. N. Uma abordagem funcionalista da hipotaxe adverbial em português. In: CAMPOS, O. G. L. A. S. (Org.). Descrição do português: abordagens funcionalistas. Araraquara, S. P.: Curso de Pós-Graduação em Letras - SCL - AR, 1999.

DIK, S. C. et al. The semantics of conditionals. In: NUYTS, J.; BOLKESTEIN, A. M.; VET, C. (Ed.). Layers and Levels of Representation in Language Theory: a functional view. Amsterdam/Philadelphia: John Benjamins, 1990. p. 233-261.

FERREIRA, A. B. F. A variação posicional das orações condicionais: uma análise funcional-discursiva. 1997. 138 f. Dissertação (Mestrado em Letras: Língua Portuguesa) - Departamento de Letras, Pontifícia Universidade Católica, Rio de Janeiro, 1997.

GRYNER, H. Graus de vinculação nas cláusulas condicionais. Cadernos de Estudos Linguísticos, v. 28, p. 69-83, 1995.

HIRATA, F. B. M. A hipotaxe adverbial condicional no português escrito contemporâneo do Brasil. 1999. 231 f. Dissertação (Mestrado) - Universidade Estadual Paulista, Araraquara, 1999. 
LUFT, C. P. et al. Novo manual de português. 7. ed. São Paulo: Globo, 1989.

MONTOLIO, E. On affirmative and negative complex conditional connectives. In: COUPER-KUHLEN,E.; KORTMANN, B. (Ed.). Cause, condition, concession, contrast: cognitive and discourse perspectives. Berlin, New York: Mouton de Gruyter, 2000.

NEVES, M. H. M. Gramática de usos do português. São Paulo: Editora Unesp, 2000.

NEVES, M. H. M. As construções condicionais. In: NEVES, M. H. M. (Org.) Gramática do português falado. Novos Estudos. v. VII. Campinas: Editora da UNICAMP/ FAPESP, 1999.

ROCHA LIMA, C. H. da. Gramática Normativa da Língua Portuguesa. 31. ed. Rio de Janeiro: José Olympio, 1972.

VAN der AWERA, J. Language and logic. A speculative and condition-theoretic study. Amsterdam: John Benjamins, 1983.

VISCONTI, J. On English and Italian complex conditional connectives: matching features and implicatures in defining semanto-pragmatic equivalence. Language Sciences, v. 18 , n.2, p. 549-573, 1996.

VISCONTI, J. A Comparative Glossary of Conditionals in Legal Language: English, Italian, German, French. (s/d, mimeo).

VISCONTI, J. I connettivi condizionali complessi in italiano e in inglese. Uno studio contrastivo. Torino: Edizioni dell'Orso, 2000.

VISCONTI, J. Conditionals and Subjectification: Implications for a Theory of Semantic Change. In: FISHER, O. et al (Ed.). Up and Down the cline: The nature of Grammaticalization. Amsterdam/Philadelphia: John Benjamins, 2004. p. 169-192. 